\title{
PENGARUH POSTUR KERJA TERHADAP KELUHAN MUSKULOSKELETAL
}

\author{
Miftahul Hasanah*, Winarko
}

Jurusan Kesehatan Lingkungan, Politeknik Kesehatan Kemenkes Surabaya

*Email korespondensi: Mif.hasanah18@gmail.com

\begin{abstract}
ABSTRAK
Posisi kerja yang tidak tepat menyebabkan gangguan otot dan memberikan beban kerja. Ada banyak faktor yang menyebabkan gangguan muskuloskeletal pada pekerja salah satunya adalah postur tubuh. Postur tubuh adalah salah satu faktor potensial penyebab gangguan muskuloskeletal pada pekerja. Tujuan dari penelitian ini adalah untuk mengetahui pengaruh postur kerja pada gangguan muskuloskeletal pada pekerja bagian Konstruksi Hull di PT. Dok dan Perkapalan Surabaya (Persero).

Jenis penelitian ini adalah penelitian analitik observasional dengan desain cross sectional. Prosedur pengumpulan data akan dilakukan dengan mengamati pekerjaan pekerja, mewawancarai pekerja tentang gangguan muskuloskeletal menggunakan kuesioner Nordic Body Maps (NBM) dan penilaian postur kerja menggunakan metode Ovako Working Analysis System (OWAS). Jumlah sampel dalam penelitian ini sebanyak 50 pekerja bagian Konstruksi Hull. Teknik pengambilan sampel yang digunakan adalah simple random sampling. Data yang terkumpul akan dianalisis secara univariat dan bivariat dengan uji statistik yaitu chi square.

Hasil penelitian menunjukkan bahwa sebagian besar pekerja usia lebih dari 35 tahun $(88 \%)$, memiliki masa kerja lebih dari 5 tahun (88\%), memiliki kebiasaan merokok sedang $(60 \%)$, memiliki postur kerja dengan kategori sedang (58\%), dan memiliki gangguan muskuloskeletal sedang (66\%). Ada korelasi yang signifikan antara postur kerja $(p=0,00)$, usia $(p=0,00)$, masa kerja $(p=0,00)$ pada gangguan muskuloskeletal. Tidak ada efek merokok $(p=1,00)$ pada gangguan muskuloskeletal.

Dianjurkan agar perusahaan memberikan istirahat pendek (5-10 menit), memberikan dukungan kembali, rotasi pekerjaan dan pemeriksaan medis yang berkaitan dengan kondisi otot dan tulang untuk meminimalkan gangguan muskuloskeletal. Para pekerja disarankan untuk pelatihan tentang ergonomis terutama gangguan muskuloskeletal dan peregangan sebelum melakukan aktivitas kerja.
\end{abstract}

Kata Kunci: Postur Kerja, Muskuloskeletal, Pekerja

\section{PENDAHULUAN}

Ergonomi merupakan suatu disiplin ilmu yang terkait dengan interaksi manusia dengan unsur lain pada suatu sistem dan profesi yang menerapkan teori, prinsip, metode, dan data untuk mendesain dalam rangka mengoptimalkan kenyamanan dan kesehatan manusia. Tujuannya adalah untuk menurunkan tingkat risiko cidera dan meningkatkan motivasi dalam bekerja serta meningkatkan produktivitas dari aktivitas pekerjaan dalam suatu tempat kerja. Salah satu risiko ergonomi yang menyebabkan cidera tubuh akibat kerja adalah Musculoskeletal Disorders (MSD's) (Angrianti, 2017).

Menurut Internasional Labor Organization (ILO) tahun 2013, setiap tahun terjadi 2,3 juta kematian yang disebabkan oleh kecelakaan kerja dan penyakit akibat kerja. Data tersebut menyebutkan 2 juta kematian disebabkan karena penyakit akibat kerja. ILO juga melaporkan bahwa gangguan muskuloskeletal saat ini mengalami peningkatan kasus di banyak negara (ILO, 2014).

OSHA (2000), menyatakan bahwa sekitar 34\% dari total hari kerja yang hilang karena cedera dan sakit yang diakibatkan oleh Muskuloskeletal Disorder's (MSD's) sehingga memerlukan biaya kompensasi sebesar 15 sampai 20 miliar dolar US. Karyawan melaporkan hampir $600.000 \quad$ Muskuloskeletal Disorder's (MSD's) membutuhkan waktu istirahat dari pekerjaannya setiap tahun dan perusahaan harus menyisihkan $\$ 1$ setiap $\$ 3$ untuk biaya kompensasi tenaga 
kerja yang mengalami Muskuloskeletal Disorder's (MSD's).

PT. Dok dan Perkapalan Surabaya (Persero) adalah salah satu galangan kapal BUMN yang bergerak di bidang pembuatan kapal dan reparasi kapal. Hull Construction merupakan bagian yang berperan penting dalam proses reparasi kapal. Dalam melaksanakan proses kerja, seringkali postur tubuh bagian Hull Construction ditentukan oleh tugas dan lingkungan kerja.

Berdasarkan survei pendahuluan yang dilakukan, saat melakukan pengelasan banyak pekerja yang bekerja dalam postur kerja yang tidak ergonomi atau postur janggal. Postur tubuh pekerja bervariasi seperti posisi membungkuk, jongkok, tangan terangkat dan berdiri dengan sebelah kaki menekuk sehingga postur tersebut dapat mempengaruhi otot bagian bahu, punggung, pinggang, lengan dan kaki.

Berdasarkan data yang tercatat di poliklinik tahun 2017 sebanyak 25\% pekerja bagian Hull Construction pernah mengalami keluhan otot. Dari 8 pekerja bagian Hull Construction yang diwawancarai, sebanyak 4 pekerja (50\%) merasakan keluhan nyeri pada pinggang, bahu, dan lengan, sebanyak 2 pekerja $(25 \%)$ merasakan keluhan pada punggung dan sebanyak 2 pekerja (25\%) merasakan keluhan pada punggung dan kaki.

Tujuan dari penelitian ini adalah mengetahui pengaruh postur kerja terhadap keluhan muskuloskeletal pada tenaga kerja bagian Hull Construction di PT. Dok dan Perkapalan Surabaya (Persero) Tahun 2018).

\section{METODE PENELITIAN}

Jenis penelitian ini adalah observasional dengan analisis secara analitik dengan desain penelitian digunakan adalah crosssectional. Populasi dalam penelitian ini sebanyak 57 tenaga kerja bagian Hull Construction, sedangkan sampel penelitian berjumlah 50 tenaga kerja. Data diperoleh dari hasil observasi, penilaian, dan wawancara diolah dalam bentuk tabel dan dianalisis menggunakan uji Chisquare.

\section{HASIL PENELITIAN DAN}

\section{PEMBAHASAN}

1. Faktor Individu

Berdasarkan hasil penelitian mengenai umur menunjukkan bahwa 44 tenaga kerja ( $88 \%$ ) berumur $\geq 35$ tahun dan 6 tenaga kerja (12\%) berumur < 35 tahun. Menurut Tarwaka (2015) bahwa keluhan pertama pada otot skeletal mulai dirasakan pada umur 35 tahun dan tingkat keluhan akan meningkat terus menerus sejalan dengan bertambahnya umur.

Masa kerja dalam penelitian ini menunjukkan bahwa 44 tenaga kerja (88\%) memiliki > 5 tahun dan 6 tenaga kerja $(12 \%)$ berumur $\leq 5$ tahun. Masa kerja yang lama dapat memberikan dampak positif yaitu tenaga kerja semakin berpengalaman dan mengetahui risiko bahaya yang akan diterima, sedangkan dampak negatifnya adalah tenaga kerja merasa sudah ahli dalam pekerjaanya namun secara tidak sadar pekerjaan tersebut dapat membahayakan dirinya (Kurnianto, 2013).

Kebiasaan merokok dalam penelitian ini menunjukkan bahwa 30 tenaga kerja (60\%) termasuk perokok sedang, 2 orang tenaga kerja (4\%) termasuk perokok ringan, dan 18 tenaga kerja (36\%) termasuk bukan perokok. kebiasaan merokok dapat menurunkan kapasitas paru - paru, sehingga kemampuan untuk mengkonsumsi oksigen menurun yang mengakibatkan tingkat kesegaran tubuh menurun. Apabila yang bersangkutan harus melakukan tugas yang membuat pengerahan tenaga, maka akan mudah lelah karena kandungan oksigen dalam darah lemah, pembakaran karbohidrat terhambat sehingga terjadinya tumpukan asam laktat dan akhirnya timbul rasa nyeri otot (Tarwaka, 2015).

2. Postur Kerja

Berdasarkan penelitian mengenai postur kerja menunjukan bahwa 8 tenaga kerja $(16 \%)$ melakukan postur kerja kategori sangat tinggi, 29 tenaga kerja (58\%) melakukan postur 
kerja kategori sedang, dan 13 tenaga kerja (26\%) melakukan postur kerja kategori rendah.

Postur kerja merupakan pengaturan sikap tubuh saat bekerja. Sikap kerja yang berbeda akan menghasilkan kekuatan yang berbeda pula. Dalam melakukakan aktivitas kerja pada tenaga kerja Hull Construction banyak yang melakukan pekerjaan dengan postur kerja yang tidak alamiah atau postur janggal seperti posisi membungkuk, dilakukan dengan posisi jongkok dan kedua lengan berada dibawah dan di atas level bahu. Menurut Humantech dalam Kurnianto (2013) menjelaskan bahwa salah satu faktor risiko ergonomi yang dapat menyebabkan terjadinya gangguan penyakit, atau cidera pada sistem muskuloskeletal adalah postur janggal. Beberapa postur janggal yang mempunyai risiko terjadinya gangguan pada sistem muskuloskeletal yaitu punggung membungkuk, kaki menekuk, dan berdiri pada satu kaki dimana tubuh bertumpu pada satu kaki. Semakin tinggi risiko pekerjaan maka semakin tinggi peluang seseorang untuk mengalami keluhan muskuloskeletal.

Postur kerja dengan kategori sedang perlu dilakukannya perbaikan karena postur tersebut dapat berpotensi menyebabkan keluhan pada sistem muskuloskeletal dan untuk postur kerja dengan kategori sangat tinggi perbaikan perlu dilakukan sekarang juga karena dari postur kerja tersebut efeknya sangat berbahaya pada sistem muskuloskeletal.

3. Keluhan Muskuloskeletal

Berdasarkan hasil penelitian menunjukkan bahwa 6 tenaga kerja $(12 \%)$ mengalami keluhan muskuloskeletal kategori tinggi, 33 tenaga kerja mengalami keluhan muskuloskeletal kategori sedang, dan 11 tenaga kerja (22\%) mengalami keluhan muskuloskeletal kategori rendah. Keluhan muskuloskeletal adalah keluhan pada bagian otot skeletal atau otot rangka yang dirasakan oleh seseorang mulai dari keluhan ringan hingga keluhan sangat sakit. Menurut Tarwaka (2015) menjelaskan bahwa terdapat beberapa faktor penyebab terjadinya keluhan pada sistem muskuloskeletal yaitu peregangan otot yang berlebihan, sikap kerja tidak alamiah, dan aktivitas berulang. Sikap kerja yang tidak alamiah atau postur janggal seperti membungkuk, jongkok, dan kedua tangan berada diatas level bahu dapat mempengaruhi sistem muskuloskeletal karena semakin jauh posisi bagian tubuh dari pusat gravitasi maka semakin tinggi pula risiko terjadinya keluhan otot skeletal.

4. Pengaruh postur kerja Terhadap Keluhan Muskuloskeletal

Tabel 1

PENGARUH POSTUR KERJA TERHADAP KELUHAN MUSKULOSKELETAL PADA TENAGA KERJA

\begin{tabular}{|c|c|c|c|c|c|c|c|c|}
\hline \multirow{3}{*}{ Postur kerja } & \multicolumn{6}{|c|}{ Keluhan Muskuloskeletal } & \multirow{2}{*}{\multicolumn{2}{|c|}{ Total }} \\
\hline & \multicolumn{2}{|c|}{ Rendah } & \multicolumn{2}{|c|}{ Sedang } & \multicolumn{2}{|c|}{ Tinggi } & & \\
\hline & $\mathrm{n}$ & $\%$ & $\mathrm{n}$ & $\%$ & $\mathrm{~N}$ & $\%$ & $\mathrm{~N}$ & $\%$ \\
\hline Rendah & 5 & 10,0 & 8 & 16,0 & 0 & 0 & 13 & 26,0 \\
\hline Sedang & 6 & 12,0 & 23 & 46,0 & 0 & 0 & 29 & 58,0 \\
\hline Sangat Tinggi & 0 & 0 & 2 & 4,0 & 6 & 12,0 & 8 & 16,0 \\
\hline Total & 11 & 22,0 & 33 & 66,0 & 6 & 12,0 & 50 & 100 \\
\hline \multicolumn{4}{|c|}{0,05} & \multicolumn{5}{|c|}{$\rho_{\text {value }}=0,00$} \\
\hline
\end{tabular}

Tabel 1 menunjukkan bahwa tenaga kerja yang memiliki postur kerja kategori sangat tinggi mengalami keluhan muskuloskeletal, sedangkan tenaga kerja yang memiliki postur kerja kategori rendah tidak mengalami keluhan atau keluhan muskuloskeletal kategori rendah. Hal ini didukung dengan hasil uji 
chi-square bahwa ( $\rho$ value $<0,05$ ) yang berarti ada pengaruh antara postur kerja terhadap keluhan muskuloskeletal.

Keluhan otot skeletal umumnya terjadi karena konstraksi otot yang berlebihan akibat pemberian beban kerja yang terlalu berat, aktivitas berulang, dan sikap kerja yang tidak alamiah yang mana sikap kerja menyebabkan posisi tubuh bergerak menjauhi pusat gravitasi sehingga risiko terjadinya keluhan otot skeletal semakin tinggi. Sikap kerja yang tidak alamiah atau postur janggal akan menyebabkan stres mekanik pada otot, ligamen, dan persendian sehingga menyebabkan rasa sakit pada otot skeletal. Postur janggal membutuhkan energi yang lebih besar pada beberapa bagian otot sehingga meningkatkan kerja jantung dan paru paru yang menghasilkan energi. Semakin lama bekerja dengan postur janggal, maka semakin banyak energi yang dibutuhkan untuk mempertahankan kondisi tersebut sehingga dampak kerusakan pada otot skeletal yang ditimbulkan semakin kuat.

Oleh karena itu, perlu kiranya untuk memperhatikan postur tubuh saat melakukan pekerjaan, istirahat, dan penyediaan back support, serta pemeriksaan medis terkait keadaan otot dan tulang untuk meminimalisir keluhan muskuloskeletal.

5. Pengaruh Umur Terhadap Keluhan Muskuloskeletal

Tabel 2

PENGARUH UMUR TERHADAP KELUHAN MUSKULOSKELETAL PADA TENAGA KERJA Keluhan Muskuloskeletal

\begin{tabular}{ccccccccc}
\multirow{2}{*}{ Umur } & \multicolumn{2}{c}{ Rendah } & \multicolumn{2}{c}{ Sedang } & \multicolumn{2}{c}{ Tinggi } & \multicolumn{2}{c}{ Total } \\
\cline { 2 - 7 } & $\mathrm{N}$ & $\%$ & $\mathrm{~N}$ & $\%$ & $\mathrm{~N}$ & $\%$ & $\mathrm{~N}$ & $\%$ \\
\hline$<35$ tahun & 6 & 12,0 & 0 & 0 & 0 & 0 & 6 & 12,0 \\
$\geq 35$ tahun & 5 & 10,0 & 33 & 66,0 & 6 & 12,0 & 44 & 88,0 \\
Total & 11 & 22,0 & 33 & 66,0 & 6 & 12,0 & 50 & 100 \\
\hline \multicolumn{3}{c}{$\mathrm{a}=0,05$} & \multicolumn{5}{c}{$\rho_{\text {value }}=0,00$} \\
\hline
\end{tabular}

Tabel 2 menunjukkan bahwa tenaga kerja berumur $\geq 35$ tahun $(88 \%)$ mengalami keluhan muskolskeletal, sedangkan tenaga kerja yang berumur $<35$ tahun tidak mengalami keluhan muskuloskeletal atau keluhan muskuloskeletal kategori rendah. Hal ini didukung dari hasil uji chi-square bahwa ( $\rho_{\text {value }}<0,05$ ) yang berarti ada pengaruh umur terhadap keluhan muskuloskeletal.

Keluhan skeletal mulai dirasakan pada usia kerja yaitu 25 - 65 tahun. Keluhan pertama dirasakan pada umur 35 tahun dan tingkat keluhan akan terus meningkat sejalan dengan bertambahnya umur. Hal ini terjadi dikarenakan pada umur setengah baya kekuatan dan ketahanan otot mulai menurun sehingga risiko keluhan otot meningkat.

Oleh karena itu, untuk mengurangi risiko keluhan muskuloskeletal yang ditimbulkan akibat oleh umur, sebaiknya pihak perusahaan agar lebih memperhatikan faktor individu dan kondisi fisik tenaga kerja khususnya yang berumur > 35 tahun karena semakin bertambahnya umur, kekuatan fisik tenaga kerja akan berkurang. Peregangan sebelum melakukan aktivitas kerja perlu dilakukan untuk mengurangi risiko keluhan otot dan perlunya beristirahat bilamana mulai merasakan keluhan sakit. 
6. Pengaruh Masa Kerja Terhadap keluhan Muskuloskeletal

Tabel 3

PENGARUH MASA KERJA TERHADAP KELUHAN MUSKULOSKELETAL PADA TENAGA

KERJA

\begin{tabular}{ccccccccc}
\hline & \multicolumn{9}{c}{ Keluhan Muskuloskeletal } & \multicolumn{2}{c}{ Total } \\
\cline { 2 - 7 } Masa Kerja & \multicolumn{2}{c}{ Rendah } & \multicolumn{2}{c}{ Sedang } & \multicolumn{2}{c}{ Tinggi } & & \\
\cline { 2 - 7 } & $\mathrm{n}$ & $\%$ & $\mathrm{n}$ & $\%$ & $\mathrm{n}$ & $\%$ & $\mathrm{~N}$ & $\%$ \\
\hline$\leq 5$ tahun & 6 & 12,0 & 0 & 0 & 0 & 0 & 6 & 12,0 \\
$>5$ tahun & 5 & 10,0 & 33 & 66,0 & 6 & 12,0 & 44 & 88,0 \\
Total & 11 & 22,0 & 33 & 66,0 & 6 & 12,0 & 50 & 100 \\
\hline & $\mathrm{a}=0,05$ & & \multicolumn{3}{c}{$\rho_{\text {value }}=0,00$} \\
\hline
\end{tabular}

Tabel 3 menunjukkan bahwa tenaga kerja yang memiliki masa kerja $>5$ tahun (88\%) mengalami keluhan muskuloskeletal, sedangkan tenaga kerja yang memiliki masa kerja $\leq 5$ tahun tidak mengalami keluhan muskuloskeletal atau keluhan muskuloskeletal kategori rendah. Hal ini didukung dari hasil uji chi-square bahwa $\left(\rho_{\text {value }}<0,05\right)$ yang berarti ada pengaruh masa kerja terhadap keluhan muskuloskeletal. Masa kerja yang lama dapat membuat tenaga kerja semakin berpengalaman dan mengetahui risiko yang akan diterima dari pekerjaannya, namun secara tidak sadar aktivitas pekerjaannya dapat membahayakan dirinya karena tenaga kerja merasa sudah ahli dalam melaksanakan pekerjaannya sehingga sering kali menyepelekan keluhan sakit yang dirasakan dari pekerjaannya. Masa kerja yang lama dapat menyebabkan kejenuhan pada daya tahan otot dan tulang secara fisik maupun psikis sehingga akumulasi cidera dari masa kerja yang lama tersebut mempunyai peranan untuk menimbulkan keluhan otot. karena semakin lama bekerja semakin lama orang terpajan risiko, maka semakin besar pula risiko untuk mengalami keluhan muskuloskeletal. Oleh karena itu, untuk memperkecil risiko keluhan otot perlu dilakukan job rotation akibat pekerjaan yang monoton dan safety talk untuk tenaga kerja yang baru bekerja untuk memperhatikan aspek K3 utamanya tentang ergonomi.

7. Pengaruh Kebiasaan Merokok Terhadap Keluhan Muskuloskeletal

Tabel 4

PENGARUH KEBIASAAN MEROKOK TERHADAP KELUHAN MUSKULOSKELETAL

\begin{tabular}{|c|c|c|c|c|c|c|c|c|}
\hline \multirow{3}{*}{ Kebiasaan Merokok } & \multicolumn{6}{|c|}{ Keluhan Muskuloskeletal } & \multirow{2}{*}{\multicolumn{2}{|c|}{ Total }} \\
\hline & \multicolumn{2}{|c|}{ Rendah } & \multicolumn{2}{|c|}{ Sedang } & \multicolumn{2}{|c|}{ Tinggi } & & \\
\hline & $\mathrm{N}$ & $\%$ & $\mathrm{~N}$ & $\%$ & $\mathrm{n}$ & $\%$ & $\mathrm{n}$ & $\%$ \\
\hline Bukan Perokok & 4 & 8,0 & 12 & 24,0 & 2 & 4,0 & 18 & 36,0 \\
\hline Perokok Ringan & 0 & 0 & 1 & 2,0 & 1 & 2,0 & 2 & 4,0 \\
\hline Perokok Sedang & 7 & 14,0 & 20 & 40,0 & 3 & 6,0 & 30 & 60,0 \\
\hline Total & 11 & 22,0 & 33 & 66,0 & 6 & 12,0 & 50 & 100 \\
\hline \multicolumn{4}{|c|}{$a=0,05$} & \multicolumn{5}{|c|}{$\rho_{\text {value }}=1,00$} \\
\hline
\end{tabular}

Tabel 4 menunjukkan bahwa perokok sedang mengalami keluhan muskuloskeletal dan bukan perokok juga mengalami keluhan muskulosleletal. Hal ini didukung dari hasil uji chisquare bahwa ( $\rho_{\text {value }}>0,05$ ) yang berarti tidak ada pengaruh kebiasaan merokok terhadap keluhan muskuloskeletal. Efek yang ditimbulkan bahaya rokok bersifat kronik sehingga ada kemungkinan bahwa bahaya rokok saat penelitian dilakukan belum terlihat pengaruh/ efek yang berarti pada tenaga kerja dan kemungkinan tenaga kerja yang tidak merokok banyak 
yang melakukan pekerjaan dengan risiko pekerjaan tinggi sehingga tenaga kerja juga mengalami keluhan muskuloskeletal. Meskipun kebiasaan merokok berperan untuk menyebabkan keluhan muskuloskeletal, namun ada faktor lain yang lebih besar pengaruhnya seperti usia, masa kerja, indeks masa tubuh, kebiasaan olahraga, dan lain lain yang berpotensi menyebabkan keluhan muskuloskeletal.

\section{KESIMPULAN}

Ada pengaruh postur kerja, umur, masa kerja dan kebiasaan merokok terhadap keluhan muskuloskeletal di PT. Dok dan Perkapalan Surabaya (Persero).

\section{SARAN}

PT. Dok dan Perkapalan Surabaya (Persero) dapat menghimbau tenaga kerja untuk melakukan istirahat disaat tenaga kerja sudah mulai merasakan keluhan pada otot tubuh. Manajemen perusahaan melakukan rotasi pekerjaan untuk menghindari stres pada otot tubuh akibat pekerjaan monoton. Perusahaan dapat menyediakan back support untuk menyokong pinggang dan punggung disaat posisi membungkuk. Perusahaan meningkatkan safety talk dan pelatihan tentang K3 khususnya bahaya ergonomi.

\section{DAFTAR PUSTAKA}

Angrianti, Siska Maulina, 2017. Hubungan Antara Postur Kerja Berdiri Dengan Keluhan Nyeri kaki Pada pekerja Aktivitas Mekanik Section welding di PT. X. Jurnal Kesehatan Masyarakat (e- Journal), 5(5) : ISSN 2356-3346.

ILO 2014, Safety and Health at Work : A Vision for Sustainable Pervention. http://www.ilo.org/WCMS 3 01214.htm (Diakses 6 Januari 2018).

Kurnianto, Rian Yuni, 2013. Gambaran Postur Kerja dan Risiko Terjadinya Muskuloskeletal pada Pekerja Bagian Welding di Area Workshop Bay 4.2 PT. Alstom Power Energy System Indonesia. The Indonesian Journal of Occuptional Safety, Health and Environment,1 (1) : 61-72.

OSHA, 2000. Ergonomics : The Study of Work. U.S. Departement oF Labour.

Tarwaka, 2015. Ergonomi Industri: Dasar - Dasar Ergonomi dan Implementasi di Tempat Kerja. Surakarta: Harapan Press. Hal 305-362. 